\title{
Determining the fabrication runtime for a buyer-vendor system with stochastic breakdown, accelerated rate, repairable items, and multi-delivery strategy
}

\author{
Singa Wang Chiu ${ }^{\mathrm{a}}$, Liang-Wei You ${ }^{\mathrm{b}}$, Peng-Cheng Sung ${ }^{\mathrm{b}^{*}}$ and Yunsen Wang,d
}

${ }^{a}$ Department of Business Administration, Chaoyang University of Technology, Taichung 413, Taiwan

${ }^{b}$ Department of Industrial Engineering \& Management, Chaoyang University of Technology, Taiwan

${ }^{c}$ School of Accounting, Southwestern University of Finance \& Economics, Chengdu, China. 611130

${ }^{d}$ Department of Accounting \& Information Systems, Rutgers Business School, Newark, NJ 07102, USA

CHRONICLE A BSTRACT

Article history:

Received April 172019

Received in Revised Format

May 232020

Accepted June 172020

Available online

June, $17 \quad 2020$

Keywords:

Production runtime

Stochastic breakdown

Accelerated manufacturing rate

Repairable items

Multi-delivery

\begin{abstract}
This study explores the optimal fabrication runtime for a buyer-vendor incorporated system featuring repairable items, stochastic breakdown, accelerated rate, and multi-delivery strategy. Operating in today's competitive global market, transnational production firms make every effort to meet client requirements in terms of the due date and quality goods. Further, they also must handle all inevitable events incurred in the manufacturing process, such as unanticipated equipment breakdowns and defective products, with caution to avoid production schedule delay and cost overrun. To examine such a vendor-buyer incorporated system, we build a model to characterize the aforementioned features in the system. The function of total system cost is derived through formulation and analyses. The optimization method and a recursive algorithm are employed to help in deriving the optimal (i.e., cost minimization) fabrication runtime for our problem. An example numerically illustrates how our model, method, and algorithm work. It also reveals the capability of our model in analyzing the impact of each and/or joint feature(s) (e.g., the breakdown, accelerated rate, rework, multi-delivery strategy) on the system's utilization, optimal runtime, total expenses, and individual cost contributor to assist in managerial decision making, and hence, enabling the firm to gain competitive advantage.
\end{abstract}

C 2020 by the authors; licensee Growing Science, Canada

\section{Introduction}

This study explores the optimal fabrication runtime for a vendor-buyer incorporated system featuring repairable items, stochastic breakdown, accelerated rate, and multi-delivery strategy. Transnational manufacturers make every effort to meet client requirements in terms of due date and quality goods to retain their competitive advantage in the global market. The acceleration of the production process is often considered to meet orders' due dates, smooth production schedules, and balance equipment's loadings. Wijngaard (1979) examined a two-stage manufacturing system wherein buffer storage inbetween stages of two unreliable fabrication units and each with different fabrication, breakdown, and repair rates. The author used regeneration points to analyze the impact on output for the aforementioned system. Distinct differential equations associated with numerical illustrations were applied to handle different assumptions on fabrication rates. Moon et al. (1991) investigated the influence of controllable manufacturing rates on a multiproduct single-machine rotation-schedule fabrication system. The authors studied the impact of changing manufacturing rates during production runs on the optimal policy/cost of

* Corresponding author

E-mail: sungpc@.cyut.edu.tw (P.C. Sung)

2020 Growing Science Ltd.

doi: $10.5267 /$ j.. jiec.2020.6.002 
the system and numerically illustrated their points and results. Sethi et al. (2000) used the verification theorem to develop an optimal control on a single-machine two-part type deterministic product system. The authors found that under certain conditions, the unique optimal control could be obtained and they also extended the model to explore the two-part type single-machine unreliable stochastic system. Sharma (2011) studied the effect of the production rate increase on the product quality in the manufacturer-supplier environments. Formulation was used, analyzed, and discussed among various cases to help in gaining managerial decisional information. AlDurgam et al. (2017) investigated a stochastic inventory model wherein a manufacturer uses various fabrication rates to cope with uncertain demand and reduce lead times, and distribution of the finished goods in multi-truckload was considered. Minimization of the total expenses of production and distribution was intended. The authors illustrated their model numerically and discussed the potential benefits that can be gained in the coordinated supply chain members. Other studies (Arslan et al., 2001; Gharbi et al., 2008; Chiu et al., 2018, 2019a) explored the influence of diverse characteristics of accelerated manufacturing rates on the production systems and supply-chain environments.

The fixed time-interval multi-delivery strategy of end products is regularly implemented by the deterministic inventory systems in buyer-vendor incorporated environments. Banerjee and Banerjee (1994) examined a single-product single-vendor multi-buyer stochastic inventory model, wherein the analytical approaches employed including a common-cycle based and an electronic data interchange. The authors showed that by using an algorithm they proposed to compute the system's operating variables, the results derived from their model can facilitate decision makings for all parties in the supplychain system. Bylka (2003) built a model based on various game scenarios on shipment frequencies to explore the competitive and cooperative policies for a dynamic decentralized batch fabricationdistribution system. The research results were discussed and compared to that in the existing literature. Hemmati et al. (2016) examined a multi-item short sea stock-routing model, wherein a many-to-many continuous-time delivery structure under a mixed fleet of ships framework is considered. The authors employed a specific two-phase hybrid matheuristic to resolve their problem. In phase one, their model was converted into the ship scheduling and routing model and solved by mathematical programming. In phase two, the neighborhood searching approach was used to further resolve the result of phase one. Finally, for small-size cases, their heuristic was compared with the exact algorithm, then their proposed model was applied to larger/realistic instances. Other works (Díaz-Mateus et al., 2018; Urrea and Pascal, 2018; Chiu et al., 2019b; Kumar et al., 2019; Batukhtin et al., 2019; Yadavalli et al., 2019) studied the influence of diverse characteristics of multi-delivery strategy on different fabrication-shipment systems in supply-chain environments.

The inevitable events, such as unanticipated equipment breakdowns and defective products, may randomly incur in the manufacturing process and cause production schedule delay and cost overrun. Thus, such events and their consequent effects/actions have brought extensive attention to production practitioners and researchers in past decades. Gershwin and Berman (1981) examined a transfer line comprising two unreliable equipment and a storage buffer, wherein the exponential service/failure and repair rates are associated with these machines. The authors employed the Markov model to analyze the parts' movement and process in the system. Certain system's behavior was numerically analyzed and illustrated. Gunasekaran et al. (1991) used mathematical modeling to explore a multi-stage, multiproduct inventory replenishment system, wherein multiple production facilities are subject to random failures. Their study aimed to investigate the impact of facility unreliability on the optimal batch size and total expenses of the system. The authors use an example to explain the system's applicability and behavior. Gong and Matsuo (1997) explored a multi-stage multiproduct fabrication system with uncertain yield, rework, and random demand. The authors aimed to develop an optimal policy to not only satisfy demand but also minimize the level of work-in-process. The authors presented proof of the optimal policy for their stochastic dynamic model. Lin and Kroll (2006) studied an imperfect EMQ model with random breakdowns. Two exponential-distribution variables were assumed in their model, namely, the times to breakdown and to shift. Their aim was to find the cost-minimization batch size for the model. Moussawi- 
Haidar et al. (2016) incorporated the screening time and rework process into the classic economic production model, and examined two scenarios for handling the imperfect quality products, namely (i) reworking them and (ii) selling them at a discount. They aimed to maximize the expected profit for the system. The renewal reward theory was used and the optimal fabrication batch size was determined. An example was used to numerically illustrate how their model work, including the deriving the lot-size solution and performing sensitivity analyses to diverse system parameters. Other studies (Ghalme et al., 2017; Zhao et al., 2018; Okonkwo et al., 2018; Rao and Singh, 2018; Iqbal et al., 2019; Dan-asabe et al., 2019; Wenbin et al., 2019; Zahedi et al., 2019) investigated the impact of diverse aspects of unreliable production equipment and imperfect quality items produced on various manufacturing systems and production planning. As prior works paid little attention to the joint influence of breakdown, accelerated rate, repairable items, and multi-delivery strategy on the fabrication runtime decision in buyer-vendor environments, this research aims to fill this gap.

\section{The proposed problem}

\subsection{Notation}

$Q=$ the replenishment batch size,

$\lambda=$ annual demand,

$t_{1 \mathrm{~A}}=$ the machine uptime in the breakdown occurring case - decision variable,

$t_{2 \mathrm{~A}}^{\prime}=$ the rework time in the breakdown occurring case,

$t^{\prime}{ }_{3 \mathrm{~A}}=$ delivery time of finished stocks in the breakdown occurring case,

$T^{\prime} \mathrm{A}=$ cycle time in the breakdown occurring case,

$t=$ time to a stochastic breakdown occurs,

$M$ = breakdown repair cost,

$\beta=$ mean Poisson distributed breakdown rate,

$t_{\mathrm{r}}=$ breakdown repair time,

$P_{1 \mathrm{~A}}=$ accelerated annual manufacturing rate,

$P_{1}=$ normal annual manufacturing rate,

$\alpha_{1}=$ the accelerated proportion as compared with $P_{1}$,

$C_{\mathrm{A}}=$ unit cost when accelerated rate $P_{1 \mathrm{~A}}$ is used,

$C=$ unit cost when normal rate $P_{1}$ is used,

$K_{\mathrm{A}}=$ setup cost when accelerated rate $P_{1 \mathrm{~A}}$ is used,

$K=$ setup cost when normal rate $P_{1}$ is used,

$\alpha_{2}=$ setup cost increase proportion when accelerated rate $P_{1 \mathrm{~A}}$ is used,

$P_{2 \mathrm{~A}}=$ accelerated annual reworking rate,

$P_{2}=$ normal annual reworking rate,

$C_{\mathrm{RA}}=$ unit reworking cost when accelerated rate $P_{2 \mathrm{~A}}$ is used,

$C_{\mathrm{R}}=$ unit reworking cost when normal rate $P_{2}$ is used,

$\alpha_{3}=$ unit cost increase proportion when accelerated rate $P_{1 \mathrm{~A}}$ and $P_{2 \mathrm{~A}}$ are used,

$t^{\prime}{ }_{\mathrm{nA}}=$ fixed time interval between two consecutive deliveries in the breakdown occurring case,

$C_{\mathrm{T}}=$ unit delivery cost,

$K_{1}=$ fixed delivery cost,

$n$ = equal-quantity deliveries per cycle,

$D=$ the number of products per delivery,

$I=$ leftover quantities at the end of each delivery time interval,

$h=$ unit holding cost,

$h_{1}=$ reworked product's unit holding cost,

$h_{2}=$ buyer stock's unit holding cost,

$x=$ random nonconforming proportion during the manufacturing process,

$d_{1 \mathrm{~A}}=$ output rate of nonconforming stocks in uptime $t_{1 \mathrm{~A}}$ when accelerated rate $P_{1 \mathrm{~A}}$ is used,

$d_{1}=$ output rate of nonconforming stocks in $t_{1 \mathrm{~A}}$ when normal rate $P_{1}$ is used, 
$C_{1}=$ safety stock's unit cost,

$h_{3}=$ safety stock's unit holding cost,

$H_{0}=$ level of end products when a breakdown occurs,

$H_{1}=$ level of finished products when uptime $t_{1 \mathrm{~A}}$ ends,

$H=$ level of finished products when rework time $t_{2 \mathrm{~A}}$ ends,

$g=t_{\mathrm{r}}$, breakdown repair time,

$t_{2 \mathrm{~A}}=$ reworking time in the no breakdown occurring case,

$t_{3 \mathrm{~A}}=$ delivery time in the no breakdown occurring case,

$T_{\mathrm{A}}=$ cycle time in the no breakdown occurring case,

$t_{\mathrm{nA}}=$ fixed time interval between two consecutive deliveries in the no breakdown occurring case,

$I(t)=$ level of perfect products at time $t$,

$I_{\mathrm{c}}(t)=$ level of buyer's products at time $t$,

$I_{\mathrm{F}}(t)=\quad$ level of safety products at time $t$,

$I_{\mathrm{d}}(t)=$ level of nonconforming products at time $t$,

$t_{1}=$ uptime for a system without breakdown, nor accelerated rate,

$t_{2}=$ reworking time for a system without breakdown, nor accelerated rate,

$t_{3}=$ delivery time for a system without breakdown, nor accelerated rate,

$T=$ cycle time for a system without breakdown, nor accelerated rate,

$\boldsymbol{T}_{\mathrm{A}}=$ cycle time for the proposed system with/without a breakdown occurring,

$E\left[\boldsymbol{T}_{\mathrm{A}}\right]=$ expected cycle time length for the proposed system,

$T C\left(t_{1 \mathrm{~A}}\right)_{1}=$ total cost per cycle in the breakdown occurring case,

$E\left[T C\left(t_{1} \mathrm{~A}\right)_{1}\right]=$ expected total cost per cycle in the breakdown occurring case,

$T C\left(t_{1 \mathrm{~A}}\right)_{2}=$ total cost per cycle in the no breakdown occurring case,

$E\left[T C\left(t_{1} \mathrm{~A}\right)_{2}\right]=$ expected total cost per cycle in the no breakdown occurring case,

$E\left[T C U\left(t_{1 \mathrm{~A}}\right)\right]=$ the expected system cost per unit time for the proposed problem, whether or not a breakdown occurs.

\subsection{Description and modeling}

This study considers the fabrication runtime problem for a vendor-buyer system with the stochastic breakdown, accelerated rate, repairable items, and multi-delivery rule. In the batch fabrication planning stage, to reduce cycle time or to smooth overall fabrication schedules, considering the option of an accelerated fabrication rate to meet annual demand $\lambda$ could be an effective approach. Subsequently, a higher unit $C_{\mathrm{A}}$ and setup $K_{\mathrm{A}}$ costs are accompanied by such an extra speedup proportion $\alpha_{1}$ in the accelerated rate $P_{1 \mathrm{~A}}$. The following are the correlations of parameters $P_{1 \mathrm{~A}}, C_{\mathrm{A}}$, and $K_{\mathrm{A}}$ and their relevant normal-rate variables:

$$
\begin{aligned}
& P_{1 \mathrm{~A}}=\left(1+\alpha_{1}\right) P_{1} \\
& C_{\mathrm{A}}=\left(1+\alpha_{3}\right) C \\
& K_{\mathrm{A}}=\left(1+\alpha_{2}\right) K
\end{aligned}
$$

Also, in real manufacturing settings, due to unforeseen issues a random $x$ proportion of nonconforming products can be manufactured at a rate $d_{1 \mathrm{~A}}$ (i.e., $x P_{1 \mathrm{~A}}$ ). No stock-out conditions are allowed, thus, we assume $P_{1 \mathrm{~A}}-d_{1 \mathrm{~A}}-\lambda>0$. All nonconforming are assumed to be repairable at an accelerated rate $P_{2 \mathrm{~A}}$ and unit rework $\operatorname{cost} C_{\mathrm{RA}}$, right after the end of uptime in each batch cycle, where

$$
\begin{aligned}
& C_{\mathrm{RA}}=\left(1+\alpha_{3}\right) C_{\mathrm{R}} \\
& P_{2 \mathrm{~A}}=\left(1+\alpha_{1}\right) P_{2}
\end{aligned}
$$

Furthermore, the fabrication equipment is subject to a Poisson distributed breakdown rate $\beta$. When a 
breakdown occurs, the equipment is promptly under repair, and once the repair job is done, the fabrication of the interrupted batch resumes immediately. The repair time $t_{\mathrm{r}}$ is assumed constant, however, if actual time spending on repair exceeds $t_{\mathrm{r}}$, then, rental equipment is in place to prevent further schedule delay. Upon accomplishment of batch production, $n$ equal-quantity shipments are transported to the buyer at fixed time interval $t_{\mathrm{nA}}^{\prime}$ during delivery time $t^{\prime}{ }_{3 \mathrm{~A}}$. Due to the nature of stochastic breakdown, the following two separate conditions are studied:

\subsubsection{Condition 1: A stochastic breakdown occurs in t1A}

The level of perfect products in condition 1 (i.e., when $t<t_{1 \mathrm{~A}}$ ) is depicted in Fig. 1. It specifies that when a breakdown occurs, the stock level accumulates to $H_{0}$; after the equipment repair task is accomplished, the stock level continues to rise to $H_{1}$ when $t_{1 \mathrm{~A}}$ ends; and when the rework is completed, the stock level ends at $H$. Then, the delivery of multiple shipments begins.

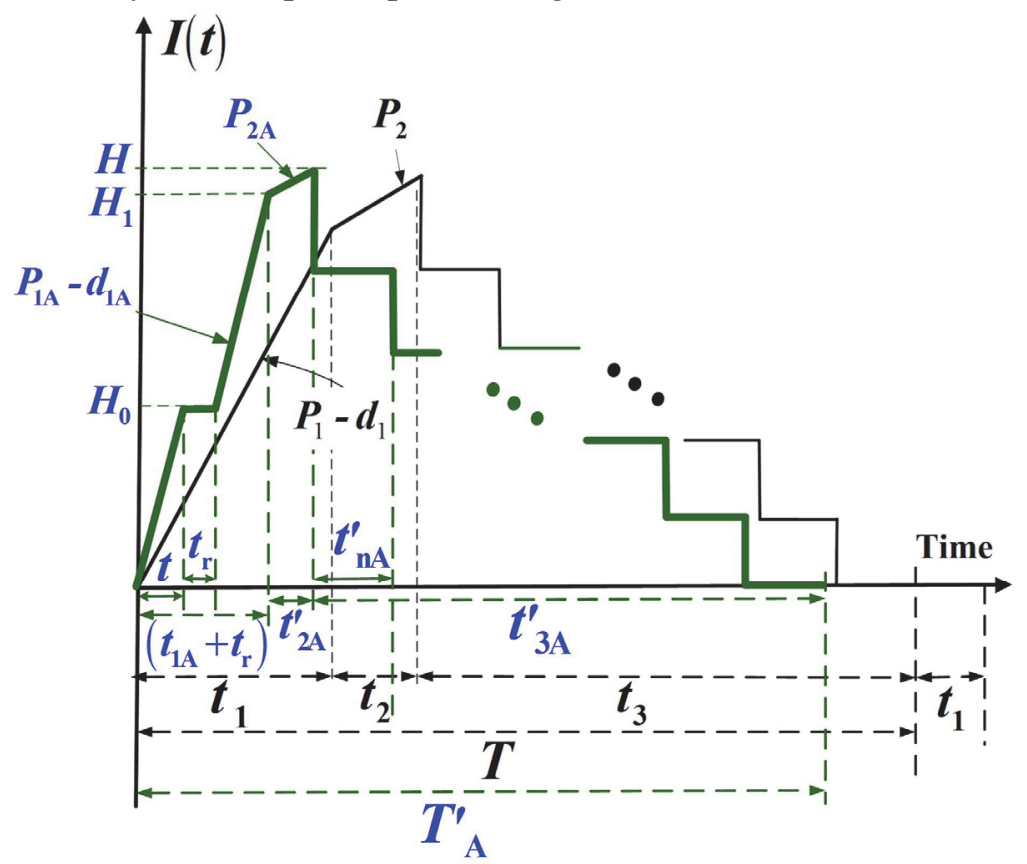

Fig. 1. The level of perfect products in condition 1 of the proposed problem (in green) as compared to that of the same problem without breakdown, nor accelerated rate option (in black)

The level of safety items in condition 1 of the proposed problem is displayed in Fig. 2. It specifies that safety items $\lambda t_{\mathrm{r}}$ are used to meet the demand during repair time, thus, they must be delivered along with the finished lot in $t^{\prime} 3 \mathrm{~A}$.

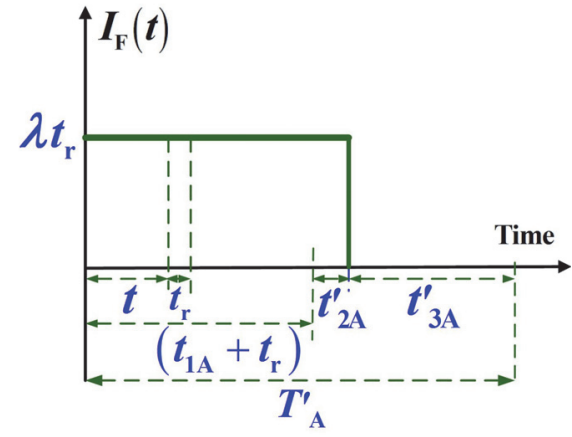

Fig. 2. The level of safety items in condition 1 of the proposed problem

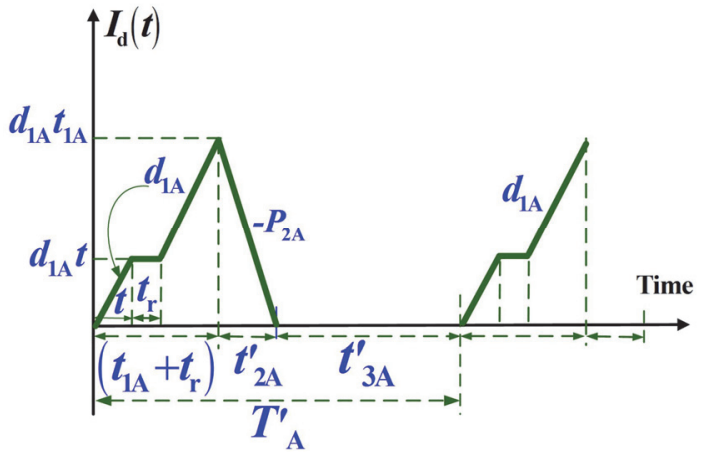

Fig. 3. The level of repairable nonconforming products in condition 1 of the proposed problem 
The level of repairable defective items in condition 1 of the proposed problem is exhibited in Fig. 3. It indicates that when a breakdown occurs, the defective items accumulate to $d_{1 \mathrm{~A}} t$; at the end of $t_{1 \mathrm{~A}}$ it comes up to $d_{1 \mathrm{~A}} t_{1 \mathrm{~A}}$, and at the end of rework time $t_{2 \mathrm{~A}}^{\prime}$ it depletes to zero. According to the aforementioned description along with observation from Fig. 1 to Fig. 3, we obtain the following formulas:

$$
\begin{aligned}
& H_{0}=\left(P_{1 \mathrm{~A}}-d_{1 \mathrm{~A}}\right) t \\
& H_{1}=\left(P_{1 \mathrm{~A}}-d_{1 \mathrm{~A}}\right) t_{1 \mathrm{~A}} \\
& t_{1 \mathrm{~A}}=\frac{Q}{P_{1 \mathrm{~A}}}=\frac{H_{1}}{P_{1 \mathrm{~A}}-d_{1 \mathrm{~A}}} \\
& t^{\prime}{ }_{2 \mathrm{~A}}=\frac{x Q}{P_{2 \mathrm{~A}}} \\
& T^{\prime}{ }_{\mathrm{A}}=t_{1 \mathrm{~A}}+t^{\prime}{ }_{2 \mathrm{~A}}+t^{\prime}{ }_{3 \mathrm{~A}}+t_{\mathrm{r}}=\frac{Q}{\lambda}+t_{\mathrm{r}} \\
& t^{\prime}{ }_{3 \mathrm{~A}}=T^{\prime}{ }_{\mathrm{A}}-\left(t_{1 \mathrm{~A}}+t^{\prime}{ }_{2 \mathrm{~A}}+t_{\mathrm{r}}\right)=\frac{Q}{\lambda}\left(1-\frac{\lambda}{P_{1 \mathrm{~A}}}-\frac{\lambda x}{P_{2 \mathrm{~A}}}\right) \\
& H^{H}=H_{1}+\left(P_{2 \mathrm{~A}}-d_{2 \mathrm{~A}}\right) t^{\prime}{ }_{2 \mathrm{~A}}+\lambda t_{r}=Q+\lambda t_{r} \\
& d_{1 \mathrm{~A}} t_{1 \mathrm{~A}}=\left(x P_{1 \mathrm{~A}}\right) t_{1 \mathrm{~A}}=x Q .
\end{aligned}
$$

The level of finished products during the delivery time in condition 1 is exhibited in Fig. 4 . The total inventories in $t^{\prime} 3 \mathrm{~A}$ (Chiu et al., 2019b) is shown in Eq. (14).

$$
\left(\frac{1}{n^{2}}\right)\left(\sum_{i=1}^{n-1} i\right) H\left(t^{\prime}{ }_{3 \mathrm{~A}}\right)=\left(\frac{n-1}{2 n}\right) H\left(t^{\prime}{ }_{3 \mathrm{~A}}\right)
$$

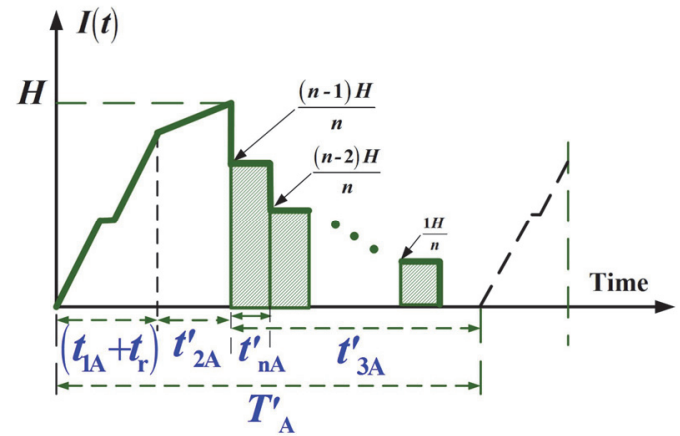

Fig. 4. The level of finished products during the $d$ elivery time in condition 1 of the problem

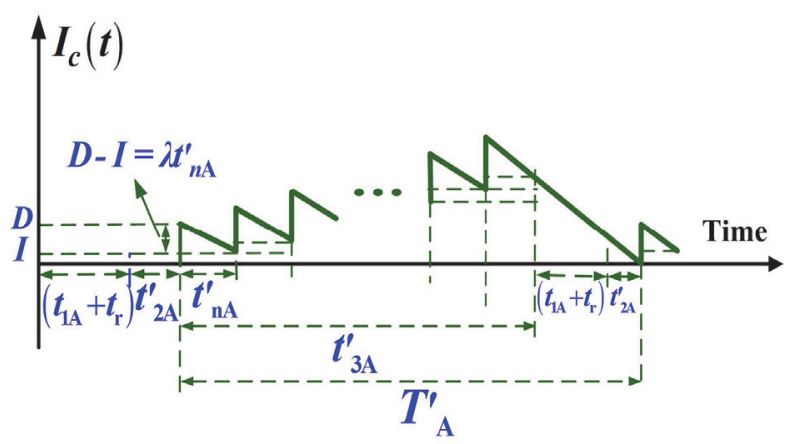

Fig. 5. Buyer's inventory status in a replenishme nt cycle in condition 1 of the problem

Buyer's inventories in a replenishment cycle in condition 1 of the proposed problem is revealed in Fig. 5. The total inventories in $T^{\prime}$ A can be obtained (Chiu et al., 2019b) as follows:

$$
\frac{n(n-1)}{2} I\left(t^{\prime}{ }_{n \mathrm{~A}}\right)+n\left(D-\frac{\lambda\left(t^{\prime}{ }_{n \mathrm{~A}}\right)}{2}\right)\left(t^{\prime}{ }_{n \mathrm{~A}}\right)+\frac{n I}{2}\left(t_{1 \mathrm{~A}}+t^{\prime}{ }_{2 \mathrm{~A}}\right)=\frac{1}{2}\left[\left(H-\lambda t^{\prime}{ }_{3 \mathrm{~A}}\right) T^{\prime}{ }_{\mathrm{A}}+\frac{H t^{\prime}{ }_{3 \mathrm{~A}}}{n}\right]
$$

Where

$$
\begin{aligned}
& I=D-\left(\lambda t^{\prime}{ }_{n \mathrm{~A}}\right) \\
& D=\frac{H}{n} .
\end{aligned}
$$


Total cost per cycle in condition $1, T C\left(t_{1 \mathrm{~A}}\right)_{1}$ includes the variable and fixed accelerated fabrication costs, breakdown repair cost, safety products related cost, rework cost, fixed and variable delivery costs, and overall holding costs in $T_{\mathrm{A}}^{\prime}$ (including reworked stocks, buyer's stocks, and the perfect and nonconforming stocks in the entire cycle) as follows:

$$
\begin{aligned}
T C\left(t_{1 \mathrm{~A}}\right)_{1} & =C_{\mathrm{A}} Q+K_{\mathrm{A}}+M+C_{1}\left(\lambda t_{r}\right)+\left[h_{3}\left(\lambda t_{r}\right)\left(t_{1 \mathrm{~A}}+t_{r}+t^{\prime}{ }_{2 \mathrm{~A}}\right)\right]+C_{\mathrm{RA}} x Q \\
+ & n K_{1}+C_{T}\left[Q+\lambda t_{r}\right]+h_{1} \frac{P_{2 \mathrm{~A}} t^{\prime}{ }_{2 \mathrm{~A}}}{2}\left(t^{\prime}{ }_{2 \mathrm{~A}}\right)+\frac{h_{2}}{2}\left[\left(H-\lambda t^{\prime}{ }_{3 \mathrm{~A}}\right) T^{\prime}{ }_{\mathrm{A}}+\frac{H t^{\prime}{ }_{3 \mathrm{~A}}}{n}\right] \\
+ & h\left[\frac{H_{1}+d_{1 \mathrm{~A}} t_{1 \mathrm{~A}}}{2}\left(t_{1 \mathrm{~A}}\right)+\left(H_{0} t_{r}\right)+\left(d_{1 \mathrm{~A}} t\right) t_{r}+\frac{H_{1}+\left(H-\lambda t_{r}\right)}{2}\left(t^{\prime}{ }_{2 \mathrm{~A}}\right)+\left(\frac{n-1}{2 n}\right) H t^{\prime}{ }_{3 \mathrm{~A}}\right]
\end{aligned}
$$

We employ the expected values of $x$ to deal with its randomness and substitute Eqs. (1) to (17) in Eq. (18), the following $E\left[T C\left(t_{1} \mathrm{~A}\right)_{1}\right]$ is obtained:

$$
\begin{aligned}
& E\left[T C\left(t_{1 \mathrm{~A}}\right)_{1}\right]=\left[\left(1+\alpha_{2}\right) K\right]+\left[\left(1+\alpha_{3}\right) C\right]\left[\left(1+\alpha_{1}\right) P_{1} t_{1 \mathrm{~A}}\right]+C_{1} \lambda g+h_{3} g\left[\left[\left(1+\alpha_{1}\right) P_{1} t_{1 \mathrm{~A}}\right] y_{1}+\lambda g\right] \\
& +M+n K_{1}+C_{T}\left[\left[\left(1+\alpha_{1}\right) P_{1} t_{1 \mathrm{~A}}\right]+\lambda g\right]+\left(1+\alpha_{3}\right) C_{R} E[x]\left[\left(1+\alpha_{1}\right) P_{1} t_{\mathrm{AA}}\right] \\
& +\frac{E[x]^{2}\left[\left(1+\alpha_{1}\right) P_{1} t_{1 \mathrm{~A}}\right]^{2}\left(h_{1}-h\right)}{2\left[\left(1+\alpha_{1}\right) P_{2}\right]}+\frac{\left[\left(1+\alpha_{1}\right) P_{1} t_{1 \mathrm{~A}}\right]^{2}\left(h_{2}-h\right)\left(1-y_{1}\right)}{2 n \lambda}+\frac{h_{2}\left[\left(1+\alpha_{1}\right) P_{1} t_{1 \mathrm{~A}}\right]^{2}}{2}\left(\frac{y_{1}}{\lambda}\right) \\
& +\frac{h\left[\left(1+\alpha_{1}\right) P_{1} t_{1 \mathrm{~A}}\right]^{2}}{2 \lambda}\left[1+\frac{\lambda E[x]}{\left(1+\alpha_{1}\right) P_{2}}\right]+h g\left[\left[\left(1+\alpha_{1}\right) P_{1}\right] t+\frac{\left(1+\alpha_{1}\right) P_{1} t_{1 \mathrm{~A}}}{2}\left(1-y_{1}\right)\right] \\
& +\frac{\left(h_{2}-h\right) g}{2 n}\left[\left(1+\alpha_{1}\right) P_{1} t_{1 \mathrm{~A}}\right]\left(1-y_{1}\right)+\frac{h_{2} g}{2}\left[\left[\left(1+\alpha_{1}\right) P_{1} t_{1 \mathrm{~A}}\right]\left(1+y_{1}\right)+\lambda g\right]
\end{aligned}
$$

where

$$
y_{1}=\frac{\lambda}{\left(1+\alpha_{1}\right)}\left[\frac{1}{P_{1}}+\frac{E[x]}{P_{2}}\right] \text {. }
$$

\subsubsection{Condition 2: No stochastic breakdowns occur in $t_{1 \mathrm{~A}}$}

The level of perfect products in condition 2 (i.e., when $t \geq t_{1 \mathrm{~A}}$ ) is displayed in Fig. 6. It specifies that the stock level accumulates to $H_{1}$ at the end of uptime, and it reaches $H$ at the end of $t_{2 \mathrm{~A}}$. Then, the delivery of multiple shipments begins.

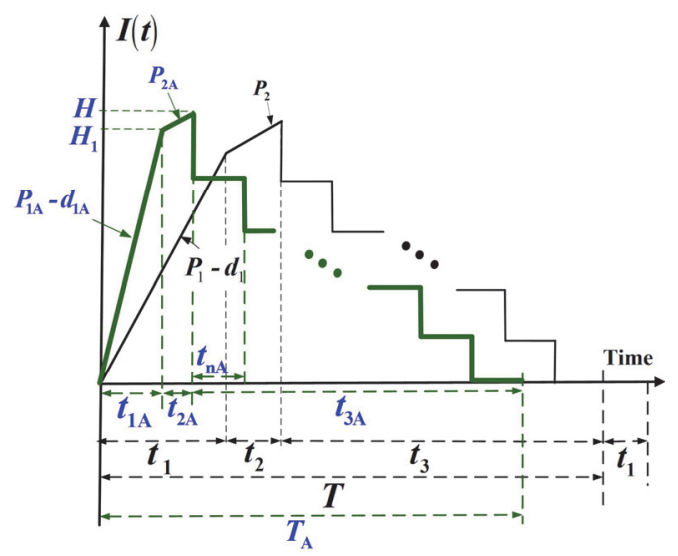

Fig. 6. The level of perfect products in condition 2 of the proposed problem (in green) as compared to that of the same problem without accelerated rate option (in black)

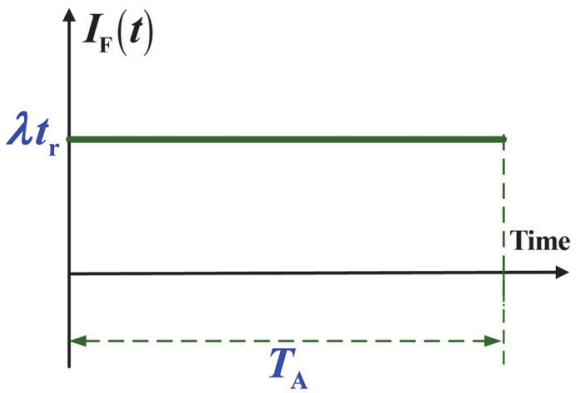

Fig. 7. The level of safety items in condition 2 of the proposed problem 
The level of safety items in condition 2 of the proposed problem is displayed in Fig. 7. It specifies that during the entire cycle time the safety items $\lambda t_{\text {r }}$ were not used because no breakdowns occurred. The status of defective products comes up to $d_{1 \mathrm{~A}} t_{1 \mathrm{~A}}$ at the end of uptime $t_{1 \mathrm{~A}}$, and it depletes to zero when rework time $t_{2 \mathrm{~A}}$ ends (refer to Fig. 3 excepts that no breakdown occurs and the following parameters are used: $t_{2 \mathrm{~A}}, t_{3 \mathrm{~A}}$, and $T_{\mathrm{A}}$ ). According to the description of condition 2, along with observation from Fig. 6 to Fig. 7, we obtain the following formulas:

$$
\begin{aligned}
& H_{1}=\left(P_{1 \mathrm{~A}}-d_{1 \mathrm{~A}}\right) t_{1 \mathrm{~A}} \\
& H=H_{1}+\left(P_{2 \mathrm{~A}}-d_{2 \mathrm{~A}}\right) t_{2 \mathrm{~A}} \\
& T_{\mathrm{A}}=t_{1 \mathrm{~A}}+t_{2 \mathrm{~A}}+t_{3 \mathrm{~A}}=\frac{Q}{\lambda} \\
& t_{1 \mathrm{~A}}=\frac{Q}{P_{1 \mathrm{~A}}}=\frac{H_{1}}{P_{1 \mathrm{~A}}-d_{1 \mathrm{~A}}} \\
& t_{2 \mathrm{~A}}=\frac{x Q}{P_{2 \mathrm{~A}}} \\
& t_{3 \mathrm{~A}}=T_{\mathrm{A}}-\left(t_{1 \mathrm{~A}}+t_{2 \mathrm{~A}}\right)=\frac{Q}{\lambda}\left[1-\frac{\lambda}{P_{1 \mathrm{~A}}}-\frac{\lambda x}{P_{2 \mathrm{~A}}}\right] .
\end{aligned}
$$

For the level of perfect products in delivery time in condition 2, we can refer to Fig. 4 but replacing the following variables: $t_{2 \mathrm{~A}}, t_{\mathrm{nA}}, t_{3 \mathrm{~A}}$, and $T_{\mathrm{A}}$ in it. The total inventories in $t_{3 \mathrm{~A}}$ (Chiu et al., 2019b) is shown as follows:

$$
\left(\frac{1}{n^{2}}\right)\left(\sum_{i=1}^{n-1} i\right) H\left(t_{3 \mathrm{~A}}\right)=\left(\frac{n-1}{2 n}\right) H\left(t_{3 \mathrm{~A}}\right)
$$

For the level of buyer's inventories in a replenishment cycle in condition 2, we can refer to Fig. 5 but without having $t_{\mathrm{r}}$ and replacing the following variables: $t_{2 \mathrm{~A}}, t_{\mathrm{nA}}, t_{3 \mathrm{~A}}$, and $T_{\mathrm{A}}$ in it. The total inventories in $T_{\mathrm{A}}$ (Chiu et al., 2019b) are as follows:

$$
\frac{1}{2}\left[\left(H-\lambda t_{3 \mathrm{~A}}\right) T_{\mathrm{A}}+\frac{H t_{3 \mathrm{~A}}}{n}\right] \text {. }
$$

Therefore, $T C\left(t_{1 \mathrm{~A}}\right)_{2}$ includes the variable and fixed accelerated fabrication costs, safety products holding cost, rework cost, fixed and variable delivery costs, and overall holding costs in $T^{\prime}$ A (including reworked stocks, buyer's stocks, and the perfect and nonconforming stocks in the entire cycle) as follows:

$$
\begin{gathered}
T C\left(t_{1 \mathrm{~A}}\right)_{2}=C_{\mathrm{A}} Q+K_{\mathrm{A}}+h_{3}\left(\lambda t_{r}\right) T_{\mathrm{A}}+C_{\mathrm{RA}} x Q+\frac{h_{2}}{2}\left[\left(H-\lambda t_{3 \mathrm{~A}}\right) T_{\mathrm{A}}+\frac{H t_{3 \mathrm{~A}}}{n}\right]+n K_{1} \\
+C_{T} Q+h_{1} \frac{P_{2 \mathrm{~A}} t_{2 \mathrm{~A}}}{2}\left(t_{2 \mathrm{~A}}\right)+h\left[\frac{H_{1}+d_{1 \mathrm{~A}} t_{1 \mathrm{~A}}}{2}\left(t_{1 \mathrm{~A}}\right)+\frac{H_{1}+H}{2}\left(t_{2 \mathrm{~A}}\right)+\left(\frac{n-1}{2 n}\right) H t_{3 \mathrm{~A}}\right]
\end{gathered}
$$

We use the expected values of $x$ to deal with its randomness and substitute Eq. (13), and Eq. (20) to Eq. (27) in Eq. (28), the following $E\left[T C\left(t_{1 \mathrm{~A}}\right)_{2}\right]$ is gained:

$$
\begin{aligned}
E\left[T C\left(t_{1 \mathrm{~A}}\right)_{2}\right] & =\left[\left(1+\alpha_{2}\right) K\right]+\left[\left(1+\alpha_{3}\right) C\right]\left[\left(1+\alpha_{1}\right) P_{1} t_{1 \mathrm{~A}}\right]+n K_{1}+C_{T}\left[\left(1+\alpha_{1}\right) P_{1} t_{1 \mathrm{~A}}\right] \\
+ & \left(1+\alpha_{3}\right) C_{R} E[x]\left[\left(1+\alpha_{1}\right) P_{1} t_{1 \mathrm{~A}}\right]+h_{3} g\left[\left(1+\alpha_{1}\right) P_{1} t_{1 \mathrm{~A}}\right] \\
+ & \frac{E[x]^{2}\left[\left(1+\alpha_{1}\right) P_{1} t_{1 \mathrm{~A}}\right]^{2}\left(h_{1}-h\right)}{2\left[\left(1+\alpha_{1}\right) P_{2}\right]}+\frac{\left[\left(1+\alpha_{1}\right) P_{1} t_{1 \mathrm{~A}}\right]^{2}\left(h_{2}-h\right)\left(1-y_{1}\right)}{2 n \lambda} \\
+ & \frac{h_{2}\left[\left(1+\alpha_{1}\right) P_{1} t_{1 \mathrm{~A}}\right]^{2}}{2}\left(\frac{y_{1}}{\lambda}\right)+\frac{h\left[\left(1+\alpha_{1}\right) P_{1} t_{1 \mathrm{~A}}\right]^{2}}{2 \lambda}\left[1+\frac{\lambda E[x]}{\left(1+\alpha_{1}\right) P_{2}}\right]
\end{aligned}
$$


where

$$
y_{1}=\frac{\lambda}{\left(1+\alpha_{1}\right)}\left[\frac{1}{P_{1}}+\frac{E[x]}{P_{2}}\right]
$$

\section{Resolving the proposed problem}

Because of the Poisson distributed breakdown rate has mean $=\beta$, thus, the time to a breakdown occurrence follows the Exponential distribution with density function $\beta e^{-\beta t 1 \mathrm{~A}}$ (i.e., $f(t)$ ) and cumulative density function $\left(1-e^{-\beta t 1 \mathrm{~A}}\right)$ (i.e., $\left.\mathrm{F}(t)\right)$. Therefore, we can calculate $E\left[T C U\left(t_{1} \mathrm{~A}\right)\right]$ from Eq. (30).

$$
E\left[T C U\left(t_{1 \mathrm{~A}}\right)\right]=\frac{\left\{\int_{0}^{t_{1 \mathrm{~A}}} E\left[T C\left(t_{1 \mathrm{~A}}\right)_{1}\right] \cdot f(t) d t+\int_{t_{1 \mathrm{~A}}}^{\infty} E\left[T C\left(t_{1 \mathrm{~A}}\right)_{2}\right] \cdot f(t) d t\right\}}{E\left[\boldsymbol{T}_{\mathrm{A}}\right]}
$$

where $E\left[\boldsymbol{T}_{\mathrm{A}}\right], T_{\mathrm{A}}^{\prime}$, and $T_{\mathrm{A}}$ represent the following:

$$
\begin{aligned}
& E\left[\boldsymbol{T}_{\mathbf{A}}\right]=\int_{0}^{t_{1 \mathrm{~A}}} T_{\mathrm{A}}^{\prime} \cdot f(t) d t+\int_{t_{1 \mathrm{~A}}}^{\infty} T_{\mathrm{A}} \cdot f(t) d t \\
& T_{\mathrm{A}}^{\prime}=\frac{Q+\lambda t_{r}}{\lambda}=\frac{t_{1 \mathrm{~A}} P_{1 \mathrm{~A}}+\lambda t_{r}}{\lambda} \\
& T_{\mathrm{A}}=\frac{Q}{\lambda}=\frac{t_{1 \mathrm{~A}} P_{1 \mathrm{~A}}}{\lambda}
\end{aligned}
$$

Substitute Eq. (19), Eq. (29), and Eq. (31) in Eq. (30), together with additional derivation efforts, we gain the following $E\left[T C U\left(t_{1 \mathrm{~A}}\right)\right]$ (Appendix A shows the details):

$$
E\left[T C U\left(t_{1 \mathrm{~A}}\right)\right]=\left[\frac{\lambda}{1+\frac{\lambda g\left(1-e^{-\beta t_{\mathrm{A}}}\right)}{\left(t_{1 \mathrm{~A}}\right)\left[\left(1+\alpha_{1}\right) P_{1}\right]}}\right]\left[\frac{v_{0}}{t_{1 \mathrm{~A}}}+\frac{v_{1}}{t_{1 \mathrm{~A}}}+v_{2} e^{-\beta t_{\mathrm{A}}}+\frac{v_{3} e^{-\beta t_{1 \mathrm{~A}}}}{t_{1 \mathrm{~A}}}-v_{4} e^{-\beta t_{1 \mathrm{~A}}}+v_{4}+v_{5} t_{1 \mathrm{~A}}+v_{6}\right]
$$

Apply the first- and second-derivatives of $E\left[T C U\left(t_{1} \mathrm{~A}\right)\right]$ we obtain Eqs. (B-1) and (B-2) (see Appendix B). When Eq. (B-3) holds, we can solve $t_{1 \mathrm{~A}}$ * by setting Eq. (B-1) equal to zero. Since the first term on the RHS of Eq. (B-1) is positive, we obtain the following:

$$
\left[\begin{array}{l}
-\left(v_{0}+v_{1}\right)\left[\left(1+\alpha_{1}\right) P_{1}+e^{-\beta t_{\mathrm{AA}}} \lambda g \beta\right]-\left(v_{4}+v_{6}\right)(\lambda g)\left(e^{-\beta t_{\mathrm{A}}} \beta\left(t_{1 \mathrm{~A}}\right)+e^{-\beta t_{1 \mathrm{~A}}}-1\right) \\
+\left(v_{2}-v_{4}\right)\left[-e^{-\beta t_{\mathrm{AA}}} \beta\left(t_{1 \mathrm{~A}}\right)^{2}\left(1+\alpha_{1}\right) P_{1}-e^{-\beta t_{\mathrm{AA}}} \beta\left(t_{1 \mathrm{~A}}\right) \lambda g-e^{-2 \beta t_{1 \mathrm{~A}}} \lambda g+e^{-\beta t_{\mathrm{A}}} \lambda g\right] \\
+v_{3}\left[-e^{-\beta t_{1 \mathrm{~A}}} \beta\left(t_{1 \mathrm{~A}}\right)\left(1+\alpha_{1}\right) P_{1}-e^{-\beta t_{1 \mathrm{~A}}} \beta \lambda g-e^{-\beta t_{1 \mathrm{~A}}}\left(1+\alpha_{1}\right) P_{1}\right] \\
+v_{5}\left(t_{1 \mathrm{~A}}\right)\left[\left(t_{1 \mathrm{~A}}\right)\left(1+\alpha_{1}\right) P_{1}+2 \lambda g\left(1-e^{-\beta t_{1 \mathrm{~A}}}\right)-e^{-\beta t_{\mathrm{AA}}}\left(t_{1 \mathrm{~A}}\right) \lambda g \beta\right]
\end{array}\right]=0
$$

Let $w_{0}, w_{1}$, and $w_{2}$ denote the following:

$$
\begin{aligned}
& w_{0}=\left[\left(v_{2}-v_{4}\right)\left[-e^{-\beta t_{1 \mathrm{~A}}} \beta\left(1+\alpha_{1}\right) P_{1}\right]+v_{5}\left[\left(1+\alpha_{1}\right) P_{1}-e^{-\beta t_{1}} \lambda g \beta\right]\right] \\
& w_{1}=-\left(e^{-\beta t_{\mathrm{A}}} \beta\right)\left[\left(v_{4}+v_{6}\right)(\lambda g)+\left(v_{2}-v_{4}\right)(\lambda g)+v_{3}\left(1+\alpha_{1}\right) P_{1}\right]+v_{5}\left[2 \lambda g\left(1-e^{-\beta t_{\mathrm{A}}}\right)\right] \\
& w_{2}=\left[\begin{array}{l}
-\left(v_{0}+v_{1}\right)\left[\left(1+\alpha_{1}\right) P_{1}+e^{-\beta t_{1}} \lambda g \beta\right]-\left(v_{4}+v_{6}\right)(\lambda g)\left(e^{-\beta t_{1}}-1\right) \\
+\left(v_{2}-v_{4}\right) \lambda g\left(-e^{-2 \beta t_{\perp}}+e^{-\beta t_{1}}\right)-v_{3} e^{-\beta t_{\perp}}\left[\beta \lambda g+\left(1+\alpha_{1}\right) P_{1}\right]
\end{array}\right]
\end{aligned}
$$

Eq. (35) is rearranged as follows: 


$$
w_{0}\left(t_{1 \mathrm{~A}}\right)^{2}+w_{1}\left(t_{1 \mathrm{~A}}\right)+w_{2}=0
$$

Apply the square root solution, the following $t_{\mathrm{A}} *$ is determined:

$$
t_{1 \mathrm{~A}}{ }^{*}=\frac{-w_{1} \pm \sqrt{w_{1}^{2}-4 w_{0} w_{2}}}{2 w_{0}}
$$

Since $F\left(t_{1 \mathrm{~A}}\right)=\left(1-e^{-\beta t 1 \mathrm{~A}}\right)$ is over the range $[0,1]$, so does its complement $e^{-\beta t 1 \mathrm{~A}}$. Also, Eq. (35) can be further rearranged as follows:

$$
e^{-\beta t_{\mathrm{AA}}}=\frac{-\left(v_{0}+v_{1}\right)\left(1+\alpha_{1}\right) P_{1}+\left(v_{4}+v_{6}\right)(\lambda g)+v_{5} t_{1 \mathrm{~A}}\left[t_{1 \mathrm{~A}}\left(1+\alpha_{1}\right) P_{1}+2 \lambda g\right]}{\left\{\begin{array}{l}
\left(v_{0}+v_{1}\right) \lambda g \beta+\left(v_{4}+v_{6}\right) \lambda g\left(\beta t_{1 \mathrm{~A}}+1\right)+v_{3}\left[\beta \lambda g+\left(1+\alpha_{1}\right) P_{1}\left(1+\beta t_{1 \mathrm{~A}}\right)\right] \\
+\left(v_{2}-v_{4}\right)\left[\beta t_{1 \mathrm{~A}}^{2}\left(1+\alpha_{1}\right) P_{1}+\lambda g\left(\beta t_{1 \mathrm{~A}}+e^{-\beta t_{\mathrm{A}}}-1\right)\right]+v_{5} \lambda g t_{1 \mathrm{~A}}\left(2+t_{1 \mathrm{~A}} \beta\right)
\end{array}\right\}}
$$

We start with the bound of $e^{-\beta t 1 \mathrm{~A}}$ to search for the optimal $t_{1 \mathrm{~A}} *$. Initially, apply Eq. (37) using $e^{-\beta t 1 \mathrm{~A}}=0$ and $e^{-\beta t 1 \mathrm{~A}}=1$ to obtain the initial bound for $t_{1 \mathrm{~A}}$ (i.e., $t_{1 \mathrm{AU}}$ and $t_{1 \mathrm{AL}}$ ). Next, using the current $t_{1 \mathrm{AU}}$ and $t_{1 \mathrm{AL}}$ to gain the update values of $e^{-\beta t 1 \mathrm{AU}}$ and $e^{-\beta t 1 \mathrm{AL}}$. Then, re-apply Eq. (37) using the current $e^{-\beta t 1 \mathrm{AU}}$ and $e^{-}$ $\beta t_{1 \mathrm{AL}}$ to obtain a set of update bounds $t_{1 \mathrm{AU}}$ and $t_{1 \mathrm{AL}}$. If $t_{1 \mathrm{AU}}=t_{1 \mathrm{AL}}$, then $t_{1 \mathrm{~A}} *$ is derived (i.e., $t_{1 \mathrm{~A}} *=t_{1 \mathrm{AU}}=$ $\left.t_{1 \mathrm{AL}}\right)$; otherwise, repeat the aforementioned iterations until $t_{1 \mathrm{AU}}=t_{1 \mathrm{AL}}$.

\section{Numerical demonstration}

A numerical example with the following parameters (see Table 1) is offered to demonstrate the research result's applicability.

Table 1

The parameters used in this numerical demonstration

\begin{tabular}{cccccccccccccc}
\hline Parameters & $P_{1 \mathrm{~A}}$ & $C_{\mathrm{A}}$ & $P_{2 \mathrm{~A}}$ & $K_{\mathrm{A}}$ & $C_{\mathrm{RA}}$ & $K_{1}$ & $\mathrm{M}$ & $C_{1}$ & $\lambda$ & $h$ & $\beta$ & $\alpha_{1}$ & $\alpha_{2}$ \\
\hline Values & 15000 & 2.5 & 7500 & 220 & 1.25 & 90 & 2500 & 2.0 & 4000 & 0.4 & 1 & 0.5 & 0.1 \\
& $P_{1}$ & $C$ & $P_{2}$ & $K$ & $C_{\mathrm{R}}$ & $n$ & $g$ & $C_{\mathrm{T}}$ & $x$ & $h_{1}$ & $h_{2}$ & $h_{3}$ & $\alpha_{3}$ \\
& 10000 & 2.0 & 5000 & 200 & 1.0 & 3 & 0.018 & 0.01 & $20 \%$ & 0.4 & 1.6 & 0.4 & 0.25 \\
\hline
\end{tabular}

The prerequisite of solving the proposed problem is to ensure the convexity of $E\left[T C U\left(t_{1 \mathrm{~A}}\right)\right]$, that is $\delta\left(t_{1 \mathrm{~A}}\right)$ $>t_{1 \mathrm{~A}}>0$ (or Eq. (B-3) holds). First, let $e^{-\beta t 1 \mathrm{~A}}=0$ and $e^{-\beta t 1 \mathrm{~A}}=1$, we apply Eq. (37) with $\beta=1.0$ to obtain $t_{1 \mathrm{AU}}=0.2953$ and $t_{1 \mathrm{AL}}=0.0881$, thus find $e^{-\beta t 1 \mathrm{AU}}=0.7443$ and $e^{-\beta t 1 \mathrm{AL}}=0.9157$. Then, apply Eq. (B-3) with $e^{-\beta t 1 \mathrm{AU}}$ and $e^{-\beta t 1 \mathrm{AL}}$, respectively, so convexity of $E\left[T C U\left(t_{1 \mathrm{~A}}\right)\right]$ for $\beta=1$ is confirmed, since $\delta\left(t_{1 \mathrm{AU}}\right)=$ $0.5205>t_{1 \mathrm{AU}}=0.2953>0$ and $\delta\left(t_{1 \mathrm{AL}}\right)=0.2886>t_{1 \mathrm{AL}}=0.0881>0$. Table $\mathrm{C}$ exhibits the outcomes of more convexity tests with a wider choice of $\beta$ values to simply demonstrate the applicability of our study.

Once we confirmed the cost function is convex, a recursive algorithm proposed at the end of previous subsection can be employed to locate $t_{1 \mathrm{~A}}$ * as follows: First, apply Eq. (37) with $e^{-\beta t 1 \mathrm{~A}}=0$ and $e^{-\beta t 1 \mathrm{~A}}=1$ to gain the initial values of $t_{1 \mathrm{AU}}=0.2953$ and $t_{1 \mathrm{AL}}=0.0881$, then use them to obtain $e^{-\beta t 1 \mathrm{AU}}=0.7443$ and $e^{-\beta t 1 \mathrm{AL}}=0.9157$. Repeatedly apply Eq. (37) with current $e^{-\beta t 1 \mathrm{AU}}$ and $e^{-\beta t 1 \mathrm{AL}}$ to calculate/update $t_{1 \mathrm{AU}}$ and $t_{1 \mathrm{AL}}$, and compute/update the values of $e^{-\beta t 1 \mathrm{AU}}$ and $e^{-\beta t 1 \mathrm{AL}}$ until $t_{1 \mathrm{AU}}=t_{1 \mathrm{AL}}$. Table 2 displays the step-bystep outcomes of this recursive algorithm for finding $t_{1} \mathrm{~A}^{*}$. As a result, $t_{1 \mathrm{~A}} *=0.1213$ and by applying Eq. (34), we obtain $E\left[T C U\left(t_{1 \mathrm{~A}} *\right)\right]=\$ 13,334.92$ are obtained. The behavior of $E\left[T C U\left(t_{1 \mathrm{~A}}\right)\right]$ in relation to $t_{1 \mathrm{~A}}$ is exhibited in Fig. 7. It shows that as $t_{1 \mathrm{~A}}$ deviates from $t_{1 \mathrm{~A}} *$ (i.e., 0.1213) in both directions, $E\left[T C U\left(t_{1 \mathrm{~A}}\right)\right]$ increases significantly. 
Table 2

Step-by-step outcomes of the recursive algorithm for finding $t_{1 \mathrm{~A}} *$

\begin{tabular}{ccccccc}
\hline Iteration \# & $t_{1 \mathrm{AU}}$ & $e^{-\beta t} 1 \mathrm{AU}$ & $t_{1 \mathrm{AL}}$ & $e^{-\beta t} 1 \mathrm{AL}$ & $E\left[T C U\left(t_{1 \mathrm{AU}}\right)\right]$ & $E\left[T C U\left(t_{1 \mathrm{AL}}\right)\right]$ \\
\hline- & - & 0 & - & 1 & - & - \\
1 & $\mathbf{0 . 2 9 5 3}$ & 0.7443 & $\mathbf{0 . 0 8 8 1}$ & 0.9157 & $\$ 14,241.46$ & $\$ 13,445.95$ \\
2 & 0.1563 & 0.8553 & 0.1132 & 0.8930 & $\$ 13,403.96$ & $\$ 13,340.13$ \\
3 & 0.1293 & 0.8787 & 0.1194 & 0.8875 & $\$ 13,339.27$ & $\$ 13,335.20$ \\
4 & 0.1232 & 0.8841 & 0.1209 & 0.8861 & $\$ 13,335.17$ & $\$ 13,334.94$ \\
5 & 0.1218 & 0.8853 & 0.1212 & 0.8858 & $\$ 13,334.94$ & $\$ 13,334.92$ \\
6 & 0.1214 & 0.8856 & 0.1213 & 0.8858 & $\$ 13,334.92$ & $\$ 13,334.92$ \\
7 & 0.1214 & 0.8857 & 0.1213 & 0.8857 & $\$ 13,334.92$ & $\$ 13,334.92$ \\
8 & $\mathbf{0 . 1 2 1 3}$ & 0.8857 & $\mathbf{0 . 1 2 1 3}$ & 0.8857 & $\mathbf{\$ 1 3 , 3 3 4 . 9 2}$ & $\mathbf{\$ 1 3 , 3 3 4 . 9 2}$ \\
\hline
\end{tabular}

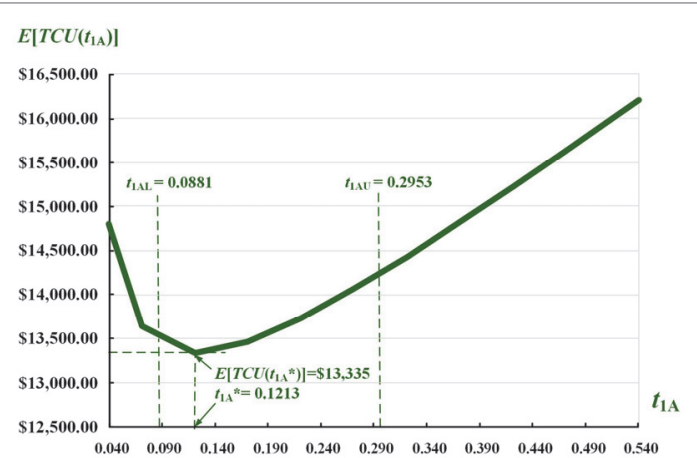

Fig. 7. The behavior of $E\left[T C U\left(t_{1 \mathrm{~A}}\right)\right]$ concerning $t_{1 \mathrm{~A}}$

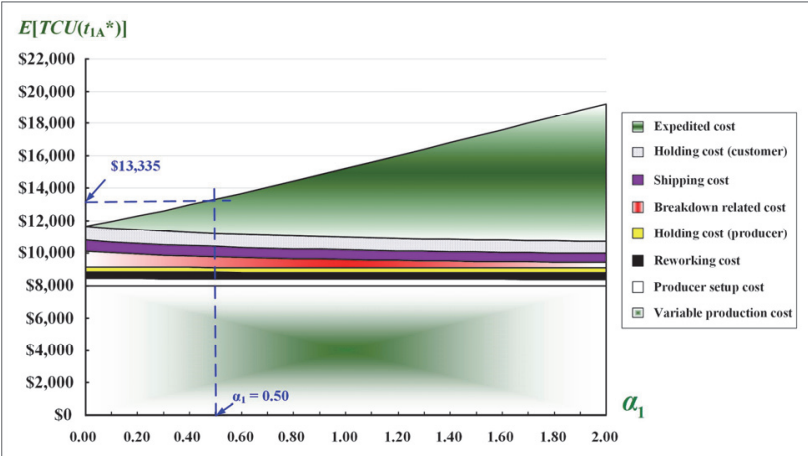

Fig. 8. The impact of changes in the accelerated ratio $\alpha_{1}$ on each cost contributor of $E\left[T C U\left(t_{1 \mathrm{~A}}{ }^{*}\right)\right]$

Fig. 8 illustrates the impact of changes in the accelerated ratio $\alpha_{1}$ on each cost contributor of $E\left[T C U\left(t_{1 \mathrm{~A}} *\right)\right]$. It indicates that the expedited cost increases drastically as $\alpha_{1}$ rises, however, the stock holding cost and breakdown relevant cost decreases slightly; and it reconfirms that at $\alpha_{1}=0.5$, $E\left[T C U\left(t_{1 \mathrm{~A}} *\right)\right]=\$ 13,335$. The behavior of $t_{1 \mathrm{~A}} *$ regarding $\alpha_{1}$ is exhibited in Fig. 9. It indicates that $t_{1 \mathrm{~A}} *$ declines drastically, as $\alpha_{1}$ increases; and it reconfirms our solution that at $\alpha_{1}=0.5, t_{1 \mathrm{~A}} *=0.1213$.

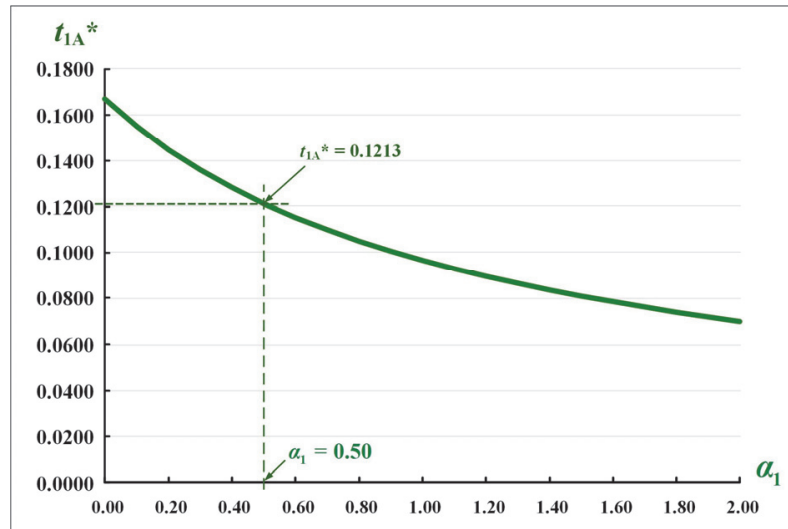

Fig. 9. The behavior of $t_{1 \mathrm{~A}}$ * regarding $\alpha_{1}$

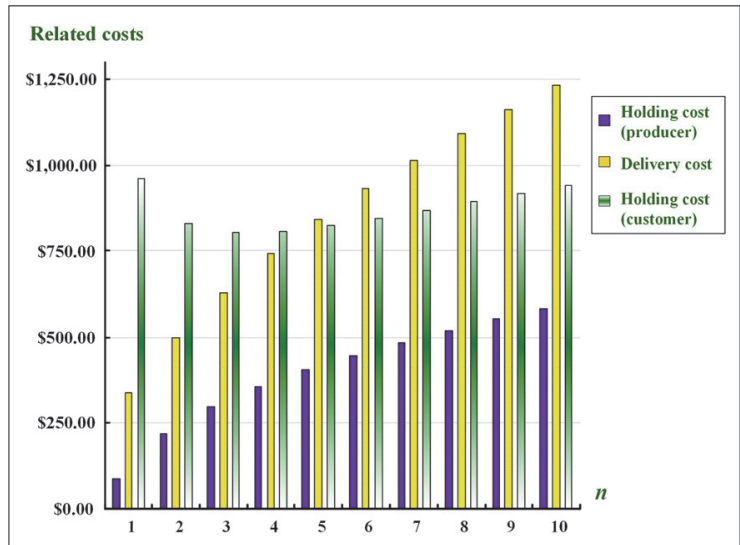

Fig. 10.The influence of differences in the frequency of delivery $n$ on relevant system cost factors

The influence of differences in the frequency of delivery $n$ on relevant system cost factors is depicted in Fig. 10. It shows that at $n=1$, the customer's stock holding cost is highest among various $n$; both the 
producer's holding and delivery costs increase significantly as $n$ goes up. Thus, we know that the frequency of delivery has more influence on the delivery cost than on in-house holding costs. Fig. 11 depicts the effect of changes in mean-time-to-breakdown $1 / \beta$ on $E\left[T C U\left(t_{1 \mathrm{~A}}{ }^{*}\right)\right]$. It reveals that $E\left[T C U\left(t_{1 \mathrm{~A}^{*}}\right)\right]$ declines, as $1 / \beta$ rises; especially when $1 / \beta \geq 0.25$ (i.e. annual breakdown instances $\beta \leq 4$ ), $E\left[T C U\left(t_{1} \mathrm{~A}^{*}\right)\right]$ starts to radically drop; and finally it reaches $\$ 12,714$, as $1 / \beta$ approaches infinite (i.e., almost no breakdown occurrence in the fabrication process). Fig. 11 also reconfirms the solution of our example: $E\left[T C U\left(t_{1 \mathrm{~A}^{*}}\right)\right]=\$ 13,335$ at $1 / \beta=1$. Fig. 12 illustrates the detailed contributors to the system cost $E\left[T C U\left(t_{1 \mathrm{~A}} *\right)\right]$. It shows that a $16.01 \%$ is contributed by the expedited fabrication cost, rate, $5.01 \%$, and $3.00 \%$ are from breakdown and rework relevant costs, and $4.73 \%$ and $6.02 \%$ of $E\left[T C U\left(t_{\left.\left.1 \mathrm{~A}^{*}\right)\right]}\right.\right.$ are regarding the product distribution and customer's stock holding costs, etc.

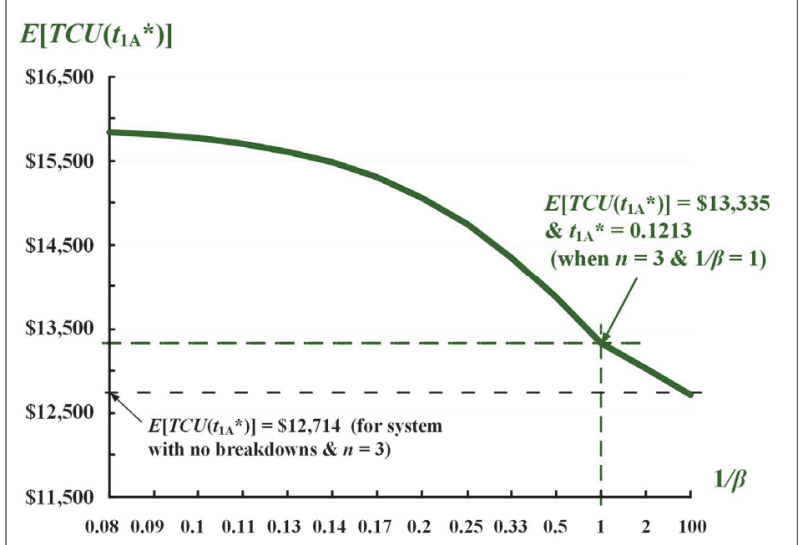

Fig. 11. The effect of changes in $1 / \beta$ on $E\left[T C U\left(t_{1 \mathrm{~A}}{ }^{*}\right)\right]$

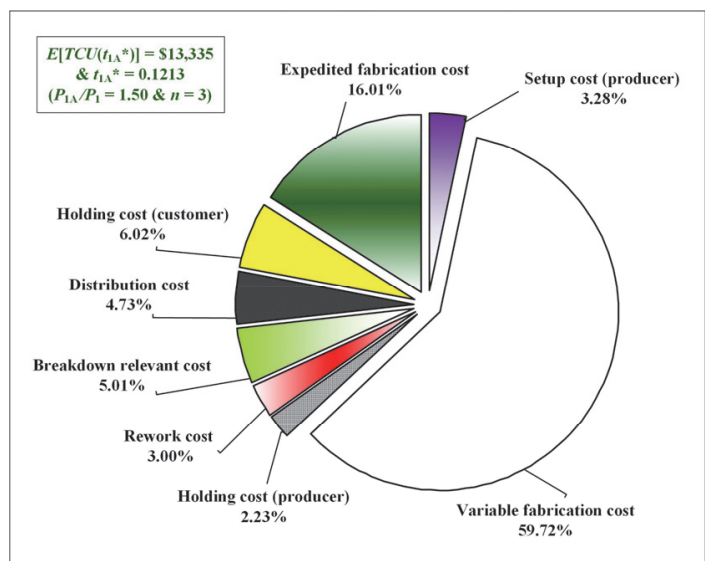

Fig. 12. The detailed contributors of $E\left[T C U\left(t_{1 \mathrm{~A}} *\right)\right]$

The joint impact of variations in the accelerated rate $\alpha_{1}$ and random defective rate $x$ on the rework cost is demonstrated in Fig. 13. It indicates that as $x$ increases, the rework cost boosts radically; and as $\alpha_{1}$ rises, the rework cost goes up slightly. Hence, we know that $x$ has more impact on the rework cost than that of $\alpha_{1}$. Fig. 14 depicts the combined influence of changes in the accelerated rework/fabrication related ratios $C_{\mathrm{RA}} / C_{\mathrm{A}}$ and $\alpha_{1}$ on $E\left[T C U\left(t_{1 \mathrm{~A}}{ }^{*}\right)\right]$. It exposes that as the ratio of $C_{\mathrm{RA}} / C_{\mathrm{A}}$ increases, $E\left[T C U\left(t_{1 \mathrm{~A}^{*}}\right)\right]$ goes up; and as the accelerated rate $\alpha_{1}$ increases, $E\left[T C U\left(t_{1 \mathrm{~A}}{ }^{*}\right)\right]$ boosts severely. Thus, $\alpha_{1}$ has more impact on $E\left[T C U\left(t_{1 \mathrm{~A}} *\right)\right]$ than that of $C_{\mathrm{RA}} / C_{\mathrm{A}}$. The effect of differences in the frequency of delivery $n$ on $E\left[T C U\left(t_{1 \mathrm{~A}}{ }^{*}\right)\right]$ is exhibited in Fig. 15. It specifies that starting from $n>2$ as $n$ increases, $E\left[T C U\left(t_{1 \mathrm{~A}}{ }^{*}\right)\right]$ boosts considerably. Fig. 16 illustrates the combined impact of changes in the accelerated rate $\alpha_{1}$ and mean- time-to-breakdown $1 / \beta$ on optimal uptime $t_{1 \mathrm{~A}} *$. It exposes that $t_{1 \mathrm{~A}}{ }^{*}$ declines significantly, as both $1 / \beta$ and $\alpha_{1}$ increases.

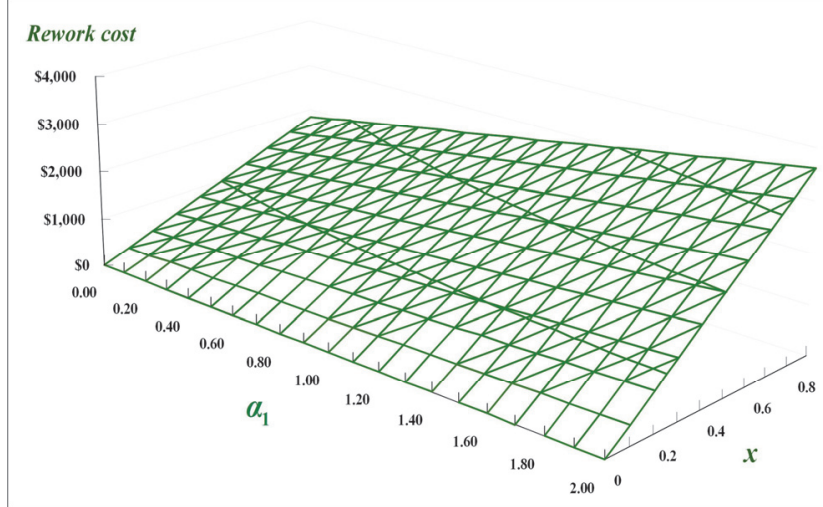

Fig. 13. The joint impact of variations in $\alpha_{1}$ and $x$ on the rework cost

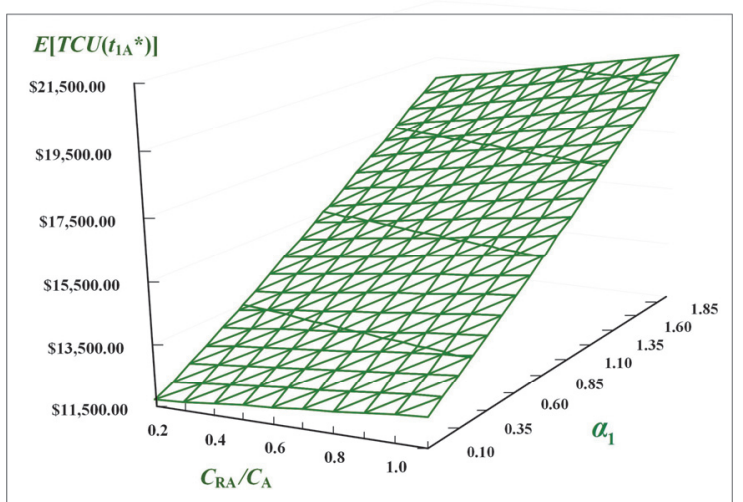

Fig. 14.The combined influence of changes in $C_{\mathrm{RA}} / C_{\mathrm{A}}$ and $\alpha_{1}$ on $E\left[T C U\left(t_{1 \mathrm{~A}}{ }^{*}\right)\right]$ 


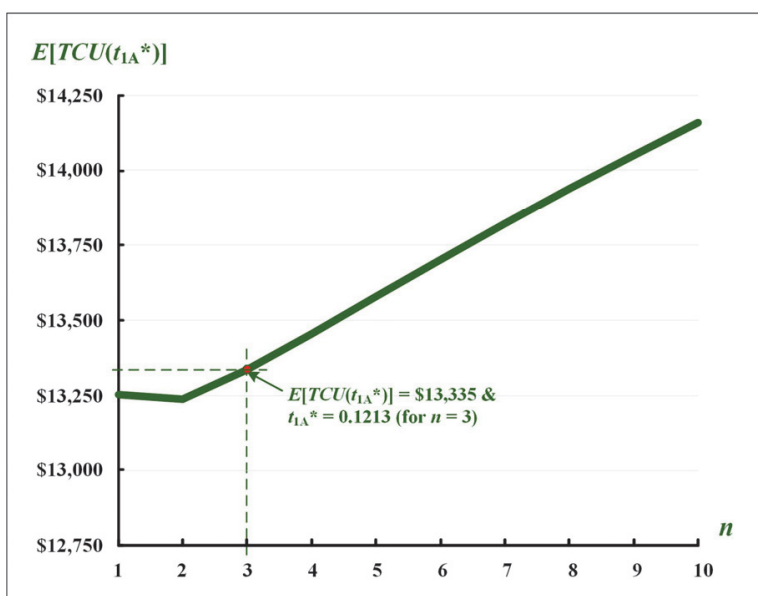

Fig. 15. The effect of differences in the frequency of delivery $n$ on $E\left[T C U\left(t_{1 \mathrm{~A}}{ }^{*}\right)\right]$

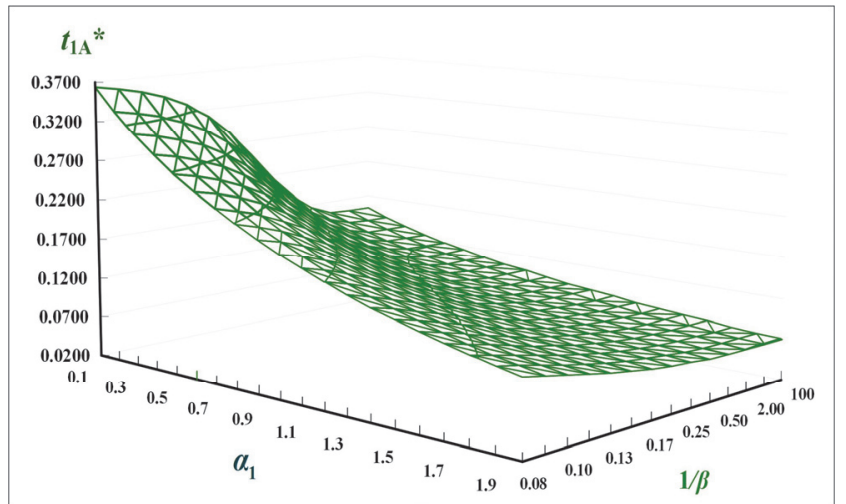

Fig. 16. The combined impact of changes in $1 / \beta$ and $\alpha_{1}$ on $t_{1 \mathrm{~A}}{ }^{*}$

\section{Conclusions}

This study explores the optimal fabrication runtime for a buyer-vendor incorporated system featuring repairable items, stochastic breakdown, accelerated rate, and multi-delivery strategy. We build a model to characterize the aforementioned features in the system, utilized formulation and analyses to derive the function of total system cost, and employed the optimization method and a recursive algorithm to find the optimal (i.e., cost minimization) fabrication runtime for the system. An example numerically illustrates how our model, method, and algorithm work (refer to the numerical demonstration section and Table 2). It also reveals the capability of our model in analyzing the impact of each and/or joint feature(s) (e.g., the breakdown, accelerated rate, rework, multi-delivery strategy) on the system's utilization, optimal runtime, total expenses, and individual cost contributor (refer to Figs. 7 to 16) to assist in managerial decision making, and hence, enabling the production firms to gain competitive advantage.

\section{Acknowledgment}

The authors appreciate the Ministry of Science and Technology of Taiwan for supporting this project (fund\#: MOST 108-2221-E-324-009).

\section{References}

AlDurgam, M., Adegbola, K., \& Glock, C.H. (2017). A single-vendor single-manufacturer integrated inventory model with stochastic demand and variable production rate. International Journal of Production Economics, 191, 335-350.

Arslan, H., Ayhan, H., \& Olsen, T.L. (2001). Analytic models for when and how to expedite in make-toorder systems. IIE Transactions, 33(11), 1019-1029.

Batukhtin, A., Batukhtina, I., Bass, M., Batukhtin, S., Kobylkin, M., Baranovskaya, M., \& Baranovskaya, A. (2019). Development and experimental verification of the mathematical model of thermal inertia for a branched heat supply system. Journal of Applied Engineering Science, 17(3), 413-424

Banerjee, A., \& Banerjee, S. (1994). A coordinated order-up-to inventory control policy for a single supplier and multiple buyers using electronic data interchange. International Journal of Production Economics, 35, 85-91.

Bylka, S. (2003). Competitive and cooperative policies for the vendor-buyer system. (2003) International Journal of Production Economics, 81-82, 533-544.

Chiu, S.W., Wu, H.Y., Chiu, Y.-S.P., \& Hwang, M.-H. (2018). Exploration of finite production rate model 
with overtime and rework of nonconforming products. Journal of King Saud University - Engineering Sciences, 30(3), 224-231.

Chiu, S.W., Huang, Y-J., Chiu, Y-S.P., Chiu, T. (2019a). Satisfying multiproduct demand with a FPRbased inventory system featuring expedited rate and scraps. International Journal of Industrial Engineering Computations, 10(3), 443-452.

Chiu, S.W., Wu, C-S., Tseng, C-T. (2019b). Incorporating an expedited rate, rework, and a multishipment policy into a multi-item stock refilling system. Operations Research Perspectives, 6, Art. No. 100115, 1-12.

Dan-asabe, B., Yaro, S.A., Yawas, D.S., Aku, S.Y. (2019). Statistical modeling and optimization of the flexural strength, water absorption and density of a doum palm-Kankara clay filler hybrid composite. Journal of King Saud University - Engineering Sciences, 31(4), 385-394.

Díaz-Mateus, Y., Forero, B., López-Ospina, H., Zambrano-Rey, G. (2018). Pricing and lot sizing optimization in a two-echelon supply chain with a constrained logit demand function. International Journal of Industrial Engineering Computations, 9(2), 205-220.

Gershwin, S.B., \& Berman, O. (1981). Analysis of transfer lines consisting of two unreliable machines with random processing times and finite storage buffers. AIIE Transactions, 13(1), 2-11.

Ghalme, S., Mankar, A., \& Bhalerao, Y. (2017). Integrated Taguchi-simulated annealing (SA) approach for analyzing wear behaviour of silicon nitride. Journal of Applied Research and Technology, 15(6), 624-632.

Gharbi, A., Pellerin, R., \& Sadr, J. (2008). Production rate control for stochastic remanufacturing systems. International Journal of Production Economics, 112(1), 37-47.

Gong, L., \& Matsuo, H. (1997). Control policy for a manufacturing system with random yield and rework. Journal of Optimization Theory and Applications, 95(1), 149-175.

Gunasekaran, A., Goyal, S.K., Subash Babu, A., \& Ramaswamy, N. (1991). Effect of machine failures in a multi-stage multi-facility and multi-product production-inventory system. International Journal of Systems Science, 22(2), 273-291.

Iqbal, A., Ahmad, S.A., \& Ojasvi (2019). Appropriate selections of distillation column control variable to improve integrating material recycle response. Journal of King Saud University - Engineering Sciences, 31(2), 106-113.

Kumar, M., Garg, D., \& Agarwal, A. (2019). An analysis of inventory attributes in leagile supply chain: Cause and effect analysis. International Journal of Mathematical, Engineering and Management Sciences, 4(4), 870-881.

Lin, G.C., \& Kroll, D.E. (2006). Economic lot sizing for an imperfect production system subject to random breakdowns. Engineering Optimization, 38(1), 73-92.

Moon, I., Gallego, G., \& Simchi-Levi, D. (1991). Controllable production rates in a family production context. International Journal of Production Research, 29(12), 2459-2470.

Okonkwo, U.C., Onokpite, E., \& Onokwai, A.O. (2018). Comparative study of the optimal ratio of biogas production from various organic wastes and weeds for digester/restarted digester. Journal of King Saud University - Engineering Sciences, 30(2), 123-129.

Rao, A.S., \& Singh, A.K. (2018). Failure analysis of stainless steel lanyard wire rope. Journal of Applied Research and Technology, 16(1), 35-40.

Sethi, S.P., Zhang, H., \& Zhang, Q. (2000). Optimal production rates in a deterministic two- product manufacturing system. Optimal Control Applications and Methods, 21(3), 125-135.

Urrea, C., \& Pascal, J. (2018). Algorithms for the generation of autonomous routes. Journal of Applied Research and Technology, 16(5), 373-383.

Wenbin, Z., Frenkel, I., Guixiang, S., Bolvashenkov, I., Kammermann, J., Herzog, H.-G., \& Khvatskin, L. (2019). Markov reward approach and reliability associated cost model for machine tools maintenance-planning optimization. International Journal of Mathematical, Engineering and Management Sciences, 4(4), 824-840.

Wijngaard, J. (1979). The effect of interstage buffer storage on the output of two unreliable production units in series, with different production rates. AIIE Transactions, 11(1), 42-47.

Yadavalli, V.S., Darbari, J.D., Bhayana, N., Jha, P.C., Agarwal, V. (2019). An integrated optimization 
model for selection of sustainable suppliers based on customers' expectations. Operations Research Perspectives, 6, Art. No. 100113, 1-16.

Zahedi, Z., Salim, A., Yusriski, R., Haris, H. (2019). Optimization of an integrated batch production and maintenance scheduling on flow shop with two machines. International Journal of Industrial Engineering Computations, 10(2), 225-238.

Zhao, X., Qian, C., Nakamura, S., Nakagawa, T. (2018). A summary of replacement policies with number of failures. International Journal of Mathematical, Engineering and Management Sciences, 3(2), 136-150.

\section{Appendix - A}

Details on obtaining Eq. (34) are as follows.

Substitute equations (19), (29), and (31) in Eq. (30), together with additional derivation efforts, we gain the following:

$$
\begin{aligned}
& E\left[\operatorname{TCU}\left(t_{1 \mathrm{~A}}\right)\right]=\left[\frac{\lambda}{1+\frac{\lambda g\left(1-e^{-\beta t_{1 \mathrm{~A}}}\right)}{\left(t_{1 \mathrm{~A}}\right)\left[\left(1+\alpha_{1}\right) P_{1}\right]}}\right] . \\
& {\left[\begin{array}{l}
\frac{\left[\left(1+\alpha_{2}\right) K\right]}{\left(t_{1 \mathrm{~A}}\right)\left[\left(1+\alpha_{1}\right) P_{1}\right]}+\frac{n K_{1}}{\left(t_{1 \mathrm{~A}}\right)\left[\left(1+\alpha_{1}\right) P_{1}\right]}+\left(1+\alpha_{3}\right) C+\left(1+\alpha_{3}\right) C_{R} E[x] \\
+C_{T}+h_{3} g\left(e^{-\beta t_{\mathrm{A}}}\right)+\frac{E[x]^{2}\left(t_{1 \mathrm{~A}}\right)\left(1+\alpha_{1}\right) P_{1}\left(h_{1}-h\right)}{2\left[\left(1+\alpha_{1}\right) P_{2}\right]}+\frac{C_{T} \lambda g\left(1-e^{-\beta t_{1 \mathrm{~A}}}\right)}{t_{1 \mathrm{~A}}\left[\left(1+\alpha_{1}\right) P_{1}\right]} \\
+\frac{\left(t_{1 \mathrm{~A}}\right)\left[\left(1+\alpha_{1}\right) P_{1}\right]\left(h_{2}-h\right)\left(1-y_{1}\right)}{2 n \lambda}+\frac{g}{2 n}\left(h_{2}-h\right)\left(1-y_{1}\right)\left(1-e^{-\beta t_{1 \mathrm{~A}}}\right) \\
+\frac{h\left(t_{1 \mathrm{~A}}\right)\left[\left(1+\alpha_{1}\right) P_{1}\right]}{2 \lambda}\left[1+\frac{\lambda E[x]}{\left(1+\alpha_{1}\right) P_{2}}\right]+\frac{h g}{t_{1 \mathrm{~A}}}\left[-t_{1 \mathrm{~A}} e^{-\beta t_{1 \mathrm{~A}}}-\frac{1}{\beta} e^{-\beta t_{1 \mathrm{~A}}}+\frac{1}{\beta}\right] \\
+\frac{M\left(1-e^{-\beta t_{1 \mathrm{~A}}}\right)}{\left(t_{1 \mathrm{~A}}\right)\left[\left(1+\alpha_{1}\right) P_{1}\right]}+\frac{C_{1} \lambda g\left(1-e^{-\beta t_{1 \mathrm{~A}}}\right)}{\left(t_{1 \mathrm{~A}}\right)\left[\left(1+\alpha_{1}\right) P_{1}\right]}+\frac{g}{2} h\left(1-y_{1}\right)\left(1-e^{-\beta t_{1 \mathrm{~A}}}\right) \\
+\frac{h_{2} \lambda g^{2}\left(1-e^{-\beta t_{1 \mathrm{~A}}}\right)}{2\left(t_{1 \mathrm{~A}}\right)\left[\left(1+\alpha_{1}\right) P_{1}\right]}+h_{3} g\left[y_{1}+\frac{\lambda g}{\left(t_{1 \mathrm{~A}}\right)\left[\left(1+\alpha_{1}\right) P_{1}\right]}\right]\left(1-e^{-\beta t_{1 \mathrm{~A}}}\right) \\
+\frac{h_{2}\left(t_{1 \mathrm{~A}}\right)\left[\left(1+\alpha_{1}\right) P_{1}\right]}{2}\left(\frac{\left.y_{1}\right)}{\lambda}\right)+\frac{g}{2} h_{2}\left(1+y_{1}\right)\left(1-e^{-\beta t_{1 \mathrm{~A}}}\right)
\end{array}\right]}
\end{aligned}
$$

Let $v_{0}, v_{1}, v_{2}, v_{3}, v_{4}, v_{5}$, and $v_{6}$ denote the following: 


$$
\begin{aligned}
v_{0} & =\frac{\left(1+\alpha_{2}\right) K}{\left(1+\alpha_{1}\right) P_{1}}+\frac{n K_{1}}{\left(1+\alpha_{1}\right) P_{1}} \\
v_{1} & =\frac{M}{\left(1+\alpha_{1}\right) P_{1}}+\frac{C_{T} \lambda g}{\left(1+\alpha_{1}\right) P_{1}}+\frac{C_{1} \lambda g}{\left(1+\alpha_{1}\right) P_{1}}+\frac{h_{3} \lambda g^{2}}{\left(1+\alpha_{1}\right) P_{1}}+\frac{h_{2} \lambda g^{2}}{2\left(1+\alpha_{1}\right) P_{1}}+\frac{h g}{\beta} \\
v_{2} & =-h g \\
v_{3} & =-\frac{M}{\left(1+\alpha_{1}\right) P_{1}}-\frac{C_{T} \lambda g}{\left(1+\alpha_{1}\right) P_{1}}-\frac{C_{1} \lambda g}{\left(1+\alpha_{1}\right) P_{1}}-\frac{h_{3} \lambda g^{2}}{\left(1+\alpha_{1}\right) P_{1}}-\frac{h_{2} \lambda g^{2}}{2\left(1+\alpha_{1}\right) P_{1}}-\frac{h g}{\beta} \\
v_{4} & =\frac{g}{2}\left[h\left(1-y_{1}\right)+\frac{\left(h_{2}-h\right)\left(1-y_{1}\right)}{n}+\left(h_{2}+2 h_{3}\right)\left(1+y_{1}\right)\right] \\
z_{5}= & \frac{E[x]^{2}\left[\left(1+\alpha_{1}\right) P_{1}\right]\left(h_{1}-h\right)}{2\left[\left(1+\alpha_{1}\right) P_{2}\right]}+\frac{\left[\left(1+\alpha_{1}\right) P_{1}\right]\left(h_{2}-h\right)\left(1-y_{1}\right)}{2 n \lambda} \\
& +\frac{h_{2}\left[\left(1+\alpha_{1}\right) P_{1}\right]}{2}\left(\frac{y_{1}}{\lambda}\right)+\frac{h\left[\left(1+\alpha_{1}\right) P_{1}\right]}{2 \lambda}\left[1+\frac{\lambda E[x]}{\left(1+\alpha_{1}\right) P_{2}}\right] \\
v_{6} & =\left[\left(1+\alpha_{3}\right) C\right]+\left[\left(1+\alpha_{3}\right) C_{R}\right] E[x]+C_{T}
\end{aligned}
$$

and

$$
y_{1}=\frac{\lambda}{\left(1+\alpha_{1}\right)}\left[\frac{1}{P_{1}}+\frac{E[x]}{P_{2}}\right] .
$$

Then, Eq. (A-1) can be rearranged as Eq. (34) as follows:

\section{Appendix - B}

$$
E\left[T C U\left(t_{1 \mathrm{~A}}\right)\right]=\left[\frac{\lambda}{1+\frac{\lambda g\left(1-e^{-\beta t_{1 \mathrm{~A}}}\right)}{\left(t_{1 \mathrm{~A}}\right)\left[\left(1+\alpha_{1}\right) P_{1}\right]}}\right]\left[\frac{v_{0}}{t_{1 \mathrm{~A}}}+\frac{v_{1}}{t_{1 \mathrm{~A}}}+v_{2} e^{-\beta t_{1 \mathrm{~A}}}+\frac{v_{3} e^{-\beta t_{1 \mathrm{~A}}}}{t_{1 \mathrm{~A}}}-v_{4} e^{-\beta t_{1 \mathrm{~A}}}+v_{4}+v_{5} t_{1 \mathrm{~A}}+v_{6}\right]
$$

Apply the first- and second-derivatives of $E\left[T C U\left(t_{1 \mathrm{~A}}\right)\right]$, we gain the following:

$$
\begin{aligned}
& \frac{d E\left[T C U\left(t_{1 \mathrm{~A}}\right)\right]}{d\left(t_{1 \mathrm{~A}}\right)}= \frac{\lambda\left(1+\alpha_{1}\right) P_{1}}{\left[\left(1+\alpha_{1}\right) P_{1}\left(t_{1 \mathrm{~A}}\right)+\lambda g\left(1-e^{-\beta t_{1 \mathrm{~A}}}\right)\right]^{2}} \cdot \\
& {\left[\begin{array}{l}
-\left(v_{0}+v_{1}\right)\left[\left(1+\alpha_{1}\right) P_{1}+e^{-\beta t_{1 \mathrm{~A}}} \lambda g \beta\right]-\left(v_{4}+v_{6}\right)(\lambda g)\left(e^{-\beta t_{\mathrm{A}}} \beta\left(t_{1 \mathrm{~A}}\right)+e^{-\beta t_{\mathrm{AA}}}-1\right) \\
+\left(v_{2}-v_{4}\right)\left[-e^{-\beta t_{1 \mathrm{~A}}} \beta\left(t_{1 \mathrm{~A}}\right)^{2}\left(1+\alpha_{1}\right) P_{1}-e^{-\beta t_{1 \mathrm{~A}}} \beta\left(t_{1 \mathrm{~A}}\right) \lambda g-e^{-2 \beta t_{\mathrm{A}}} \lambda g+e^{-\beta t_{1 \mathrm{~A}}} \lambda g\right] \\
+v_{3}\left[-e^{-\beta t_{1 \mathrm{~A}}} \beta\left(t_{1 \mathrm{~A}}\right)\left(1+\alpha_{1}\right) P_{1}-e^{-\beta t_{1 \mathrm{~A}}} \beta \lambda g-e^{-\beta t_{1 \mathrm{~A}}}\left(1+\alpha_{1}\right) P_{1}\right] \\
+v_{5}\left(t_{1 \mathrm{~A}}\right)\left[\left(t_{1 \mathrm{~A}}\right)\left(1+\alpha_{1}\right) P_{1}+2 \lambda g\left(1-e^{-\beta t_{\mathrm{1A}}}\right)-e^{-\beta t_{1 \mathrm{~A}}}\left(t_{1 \mathrm{~A}}\right) \lambda g \beta\right]
\end{array}\right.}
\end{aligned}
$$

and 


$$
\begin{aligned}
& \frac{d^{2} E\left[\operatorname{TCU}\left(t_{1 \mathrm{~A}}\right)\right]}{d\left(t_{1 \mathrm{~A}}\right)^{2}}=\frac{\lambda\left[\left(1+\alpha_{1}\right) P_{1}\right]}{\left[\left(t_{1 \mathrm{~A}}\right)\left[\left(1+\alpha_{1}\right) P_{1}\right]+\lambda g\left(1-e^{-\beta t_{1 A}}\right)\right]^{3}} .
\end{aligned}
$$

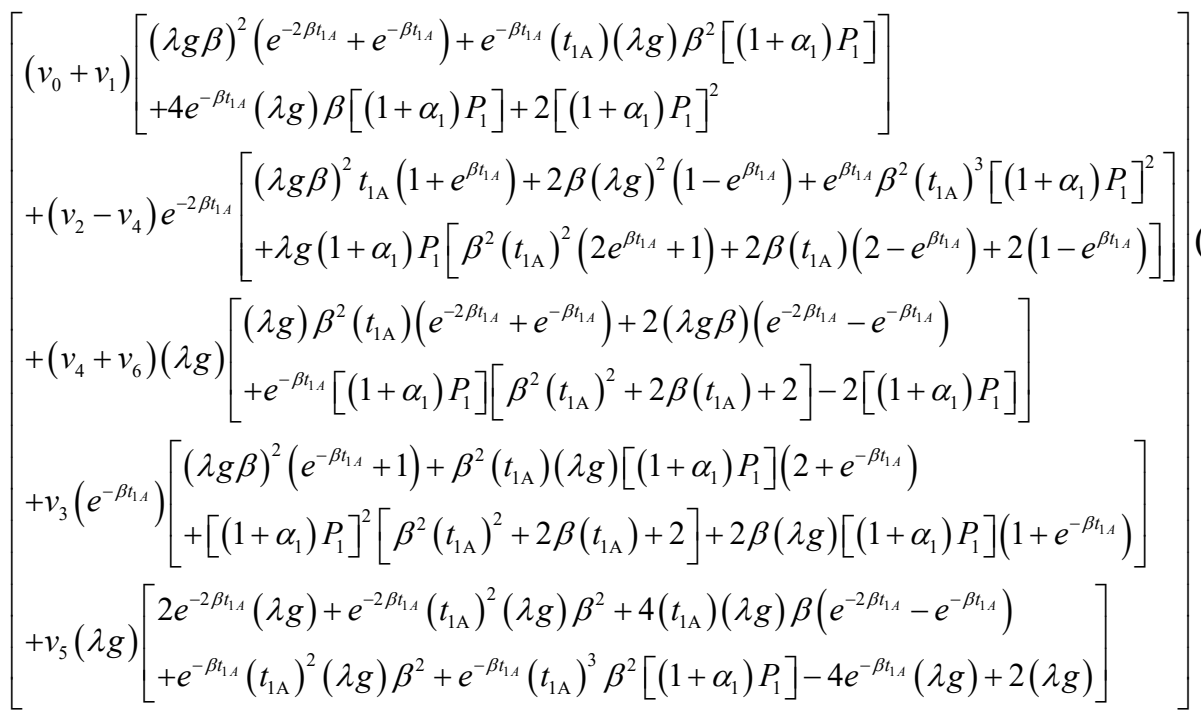

Because the first term on the right-hand side (RHS) of Eq. (B-2) is positive, so $E\left[T C U\left(t_{1 \mathrm{~A}}\right)\right]$ is convex if one can prove Eq. (B-3) holds.

$$
\begin{aligned}
& -\left(v_{0}+v_{1}\right)\left[(\lambda g \beta)^{2}\left(e^{-2 \beta t_{1,}}+e^{-\beta t_{1}}\right)+\left(1+\alpha_{1}\right) P_{1}\left[4 e^{-\beta t_{1,}}(\lambda g \beta)+2\left(1+\alpha_{1}\right) P_{1}\right]\right] \\
& -\left(v_{2}-v_{4}\right)\left(e^{-2 \beta t_{1}}\right)\left(1-e^{\beta t_{1,}}\right)\left[2 \beta(\lambda g)^{2}+2(\lambda g)\left(1+\alpha_{1}\right) P_{1}\right] \\
& -\left(v_{4}+v_{6}\right)(\lambda g)\left[2(\lambda g) \beta\left(e^{-2 \beta t_{1,}}-e^{-\beta t_{1, A}}\right)-2\left(1+\alpha_{1}\right) P_{1}\left(1-e^{-\beta t_{1} A}\right)\right] \\
& -v_{3}\left(e^{-\beta t_{1}}\right)\left[(\lambda g \beta)^{2}\left(1+e^{-\beta t_{1}}\right)+2\left(1+\alpha_{1}\right) P_{1} \beta \lambda g\left(1+e^{-\beta t_{1}}\right)+2\left[\left(1+\alpha_{1}\right) P_{1}\right]^{2}\right] \\
& \delta\left(t_{1 \mathrm{~A}}\right)=\frac{-v_{5}(\lambda g)^{2}\left(2 e^{-2 \beta t_{1, A}}-4 e^{-\beta \beta_{1, \lambda}}+2\right)}{\left[\left(v_{0}+v_{1}\right)\right]\left[e^{-\beta t_{1, A}}(\lambda g) \beta^{2}\left[\left(1+\alpha_{1}\right) P_{1}\right]\right]}>t_{1 \mathrm{~A}}>0 \\
& +\left(v_{2}-v_{4}\right)\left(e^{-2 \beta t_{1,}}\right)\left[\begin{array}{l}
(\lambda g \beta)^{2}\left(1+e^{\beta t_{1,}}\right)+e^{\beta t_{1,}} \beta^{2} t_{1 \mathrm{~A}}^{2}\left[\left(1+\alpha_{1}\right) P_{1}\right]^{2} \\
+(\lambda g)\left(1+\alpha_{1}\right) P_{1}\left[2 e^{\beta t_{1, A}} \beta^{2} t_{1 \mathrm{~A}}+\beta^{2} t_{1 \mathrm{~A}}+4 \beta-2 e^{\beta t_{1, A}} \beta\right]
\end{array}\right] \\
& +\left(v_{4}+v_{6}\right)(\lambda g \beta)\left[(\lambda g \beta)\left[e^{-2 \beta t_{1,}}+e^{-\beta t_{1,}}\right]+y_{0}\left(1+\alpha_{1}\right) P_{1}\left(e^{-\beta t_{1,}} \beta t_{1 \mathrm{~A}}+2 e^{-\beta t_{1}}\right)\right] \\
& +v_{3}\left(e^{-\beta t_{1}}\right)\left(1+\alpha_{1}\right) P_{1}\left[2 \beta^{2} \lambda g+e^{-\beta t_{1}} \beta^{2} \lambda g+\beta^{2} t_{1 \mathrm{~A}}\left(1+\alpha_{1}\right) P_{1}+2 \beta\left(1+\alpha_{1}\right) P_{1}\right] \\
& +v_{5} \lambda g\left[\lambda g \beta\left(e^{-2 \beta t_{1}} t_{1 \mathrm{~A}} \beta+4 e^{-2 \beta t_{1 A}}+e^{-\beta t_{1}} t_{1 \mathrm{~A}} \beta-4 e^{-\beta t_{1}}\right)+e^{-\beta t_{1}} t_{1 \mathrm{~A}}^{2} \beta^{2}\left(1+\alpha_{1}\right) P_{1}\right]
\end{aligned}
$$

\begin{tabular}{|c|c|c|c|c|}
\hline$\beta$ & $\delta\left(t_{1 \mathrm{AL}}\right)$ & $t_{1 \mathrm{AL}}$ & $\delta\left(t_{1 \mathrm{AU}}\right)$ & $t_{1 \mathrm{AU}}$ \\
\hline 11 & 0.0396 & 0.0185 & 0.9517 & 0.2904 \\
\hline 8 & 0.0531 & 0.0246 & 0.6303 & 0.2906 \\
\hline 5 & 0.0811 & 0.0366 & 0.4678 & 0.2910 \\
\hline 4 & 0.0985 & 0.0435 & 0.4402 & 0.2913 \\
\hline 3 & 0.1253 & 0.0531 & 0.4276 & 0.2917 \\
\hline 2 & 0.1727 & 0.0672 & 0.4389 & 0.2926 \\
\hline 1 & 0.2886 & 0.0881 & 0.5205 & 0.2953 \\
\hline 0.5 & 0.4788 & 0.1020 & 0.6965 & 0.3006 \\
\hline 0.01 & 3.8167 & 0.1183 & 4.3397 & 0.6320 \\
\hline
\end{tabular}

(B-3)

\section{Appendix - C}

Table C

More convexity tests of $E\left[T C U\left(t_{1 \mathrm{~A}}\right)\right]$ with a wider choice of $\beta$ values 
(C) 2020 by the authors; licensee Growing Science, Canada. This is an open access article distributed under the terms and conditions of the Creative Commons Attribution (CCBY) license (http://creativecommons.org/licenses/by/4.0/). 